\title{
Alguns versos de adoração e separação*
}

Roger Miguel Sulis

O poeta Théon Spanúdis (1915-1986) nasceu em Esmirna poucos anos antes do fim trágico das revoltas das populações gregas da Ásia Menor, com o incêndio da cidade e a expatriação dos sobreviventes para a Grécia. Radicou-se no Brasil em 1950, onde foi um obstinado colecionador e crítico de arte brasileira. Paralelamente, manteve uma intensa atividade poética, em grego, português e alemão.

Seus poemas eróticos, de inspiração homossexual, estão reunidos mormente no volume Versos de adoração e separação, publicado em Atenas em 1975.

Os versos aqui traduzidos constam da edição de 1979:

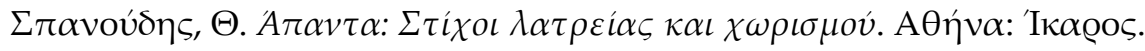
Tómos $\Gamma^{\prime}$.

* Agradeço à prof ${ }^{a}$ Maria Papadima da Universidade de Atenas pelo envio dos originais. 
Roger Miguel Sulis. Alguns versos de adoração e separação

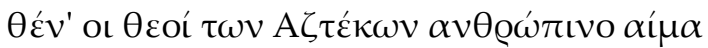

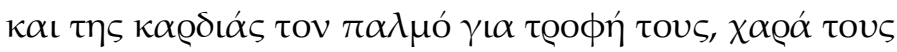

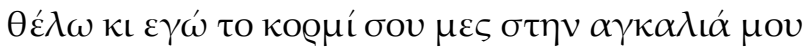

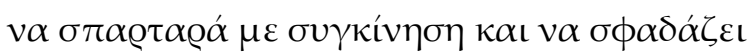

querem os deuses dos astecas sangue humano e do coração a batida por seu alimento, sua alegria

quero eu também teu corpo em meu abraço a se debater comovido e a se retorcer

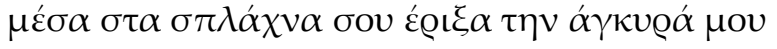

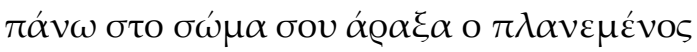

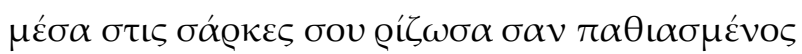

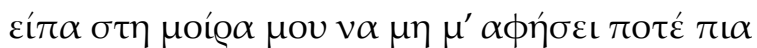

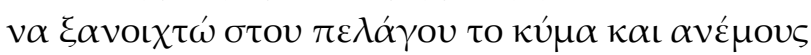

em tuas entranhas lancei minha âncora sobre teu corpo aportei, errante em tuas carnes me arraiguei exaltado disse a meu destino para jamais permitir que saísse à onda e ventos do mar 


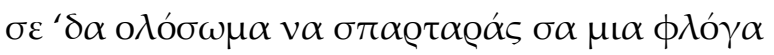

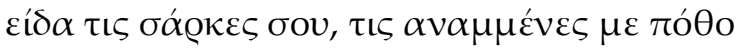

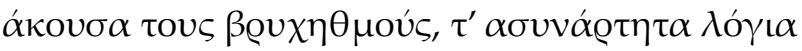

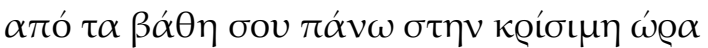

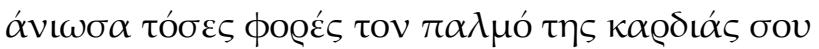

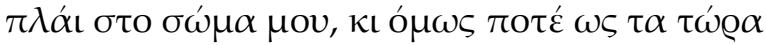

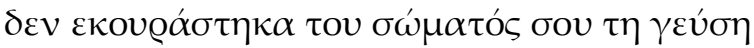

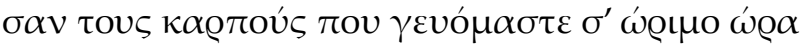
de corpo inteiro te vi tremer como uma flama vi tuas carnes, inflamadas de desejo ouvi o frêmito, palavras incoerentes de teu abismo na hora derradeira tantas vezes senti teu coração bater a meu lado, e jamais até agora cansei do sabor do teu corpo como frutos que provamos em hora madura 
Roger Miguel Sulis. Alguns versos de adoração e separação

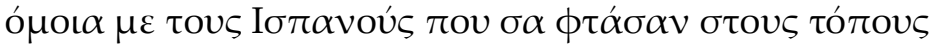

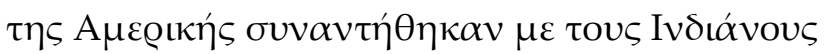

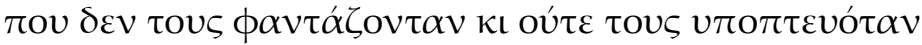

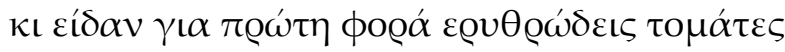

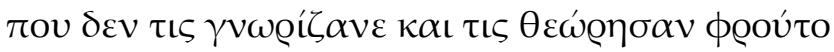

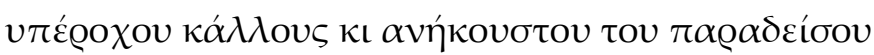

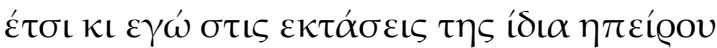

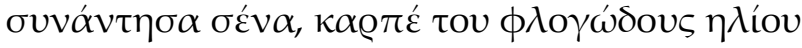

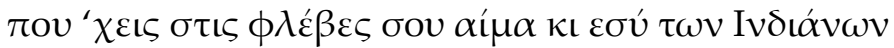

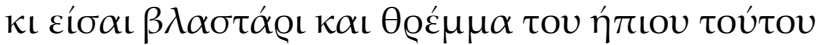

$\varepsilon \delta \alpha ́ \phi o u s$

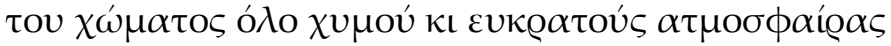

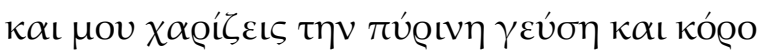

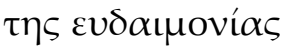


como os espanhóis que ao chegarem aos lugares

da América encontraram-se com os índios

que não os imaginavam, nem deles suspeitavam

e viram pela primeira vez tomates vermelhos,

que não conheciam, e os consideraram fruto

de sublime beleza e inaudito no paraíso

assim também eu nas extensões do mesmo continente

te encontrei fruto do sol flamejante

que tens em tuas veias o sangue, também tu, dos índios

e és broto e cria deste doce

solo

do chão todo suco e agradável atmosfera

e me presenteias o ígneo sabor e saciedade

da eudemonia 
Roger Miguel Sulis. Alguns versos de adoração e separação

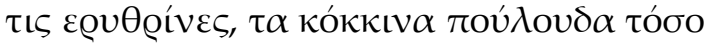

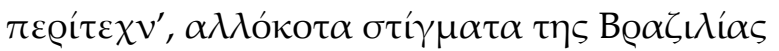

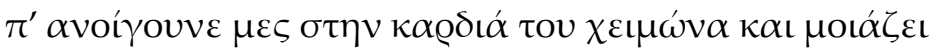

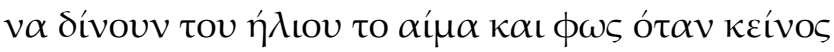

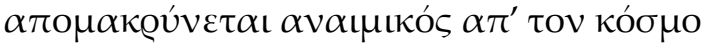

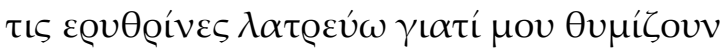

$\varepsilon \sigma \varepsilon ́ v \alpha$

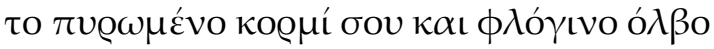

eritrinas, as flores vermelhas tão

caprichosas, insólitos estigmas do Brasil

que se abrem no coração do inverno e parecem

dar ao sol o sangue e luz quando aquele

anêmico se afasta do mundo

idolatro as eritrinas pois me lembram

de ti

teu corpo ardente e ígnea fortuna 


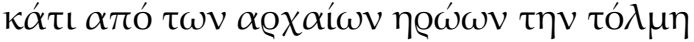

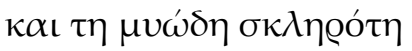

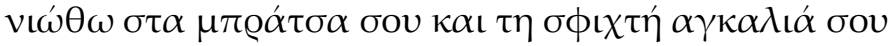

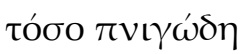

algo da audácia dos antigos herois

e do vigor musculado

sinto em teus braços e teu abraço apertado

tão sufocante 
Roger Miguel Sulis. Alguns versos de adoração e separação

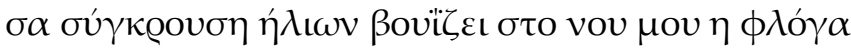

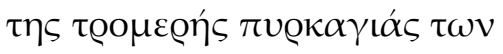

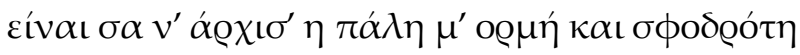

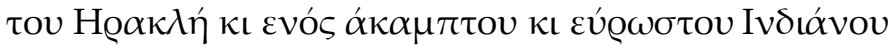

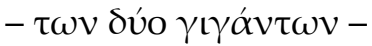

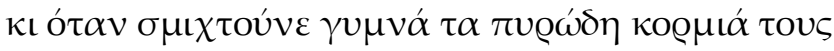

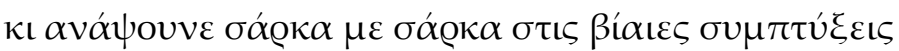

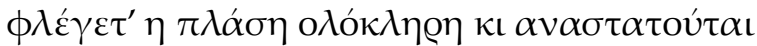
$\tau о \sigma \dot{\mu} \mu \pi \alpha v$

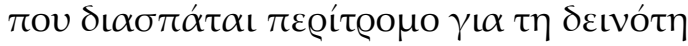

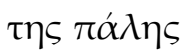

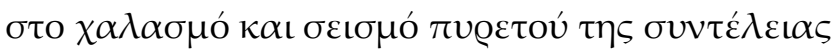


como colisão de sóis zune em minha mente a flama de seu terrível incêndio

é como se começasse a luta com ímpeto e fúria de Héracles e um indômito e veemente índio

- de dois gigantes -

e quando unem nus seus corpos ardentes

e inflamam carne com carne em violentas contrações

inflama-se toda a criação e turba-se

o universo

que se rompe aterrado com a atrocidade

da luta

no caos e sismo da febre do fim

Demais bibliografia do autor em:

http://www.dicionariodetradutores.ufsc.br/pt/TheonSpanudis.htm 